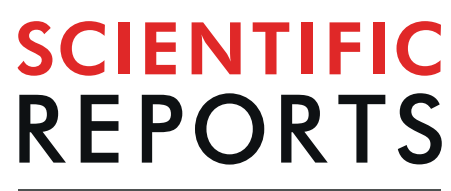

natureresearch

Check for updates

\title{
A new magnesium sheet alloy with high tensile properties and room- temperature formability
}

Renhai Shi ${ }^{1}$, Jiashi Miao ${ }^{1}$, Thomas Avey ${ }^{1}$ \& Alan A. Luo ${ }^{1,2} \bowtie$

Lightweight sheet alloys with superior mechanical performance such as high strength, ductility and formability at room temperature (RT) are desirable for high volume automotive applications. However, ductility or formability of metallic alloys at RT are generally inversely related to strength, thereby making it difficult to optimize all three simultaneously. Here we design a new magnesium sheet alloyZAXME11100 (Mg-1.0Zn-1.0Al-0.5Ca-0.4Mn-0.2Ce, wt. pct.) via CALPHAD (CALculation of PHAse Diagram) modeling and experimental validation. This new sheet alloy offers an excellent RT formability with a high Index Erichsen (I.E.) value of $7.8 \mathrm{~mm}$ in a solution-treated condition (T4), due to its weak and split basal texture and fine grain structure. The new ZAXME 11100 alloy also shows a rapid agehardening response during post-forming artificial aging treatment at $210^{\circ} \mathrm{C}$ for 1 hour (T6), resulting in a significant increase of yield strength from $159 \mathrm{MPa}$ (T4) to $270 \mathrm{MPa}$ (T6). The excellent combination of T4 ductility (31\%), T4 formability $(7.8 \mathrm{~mm})$ and T6 yield strength (270 MPa) in this new magnesium alloy is comparable to that of common $6 x x x$ series aluminum sheet alloys. Thus, this new magnesium sheet alloy is highly attractive for sheet applications in automotive and other industries.

Steels and 6xxx series aluminum (Al-Mg-Si) alloys are mostly used for automotive body panels due to their excellent formability and subsequent bake hardenability ${ }^{1,2}$. In order to meet the ever-increasing demand for vehicle weight reduction, the use of lighter structural materials has become inevitable in the automotive industry. Magnesium (Mg), the lightest structural metal, has thus attracted considerable attention for applications in automotive and other transportation industries ${ }^{3,4}$. However, compared to $6 \mathrm{xxx}$ series aluminum alloys $\mathrm{s}^{5,6}$ or steels $^{7}$, inferior mechanical properties at RT and high processing cost limit wider applications of commercial Mg sheet alloys such as AZ31 (Mg-3Al-1Zn-0.3Mn) and ZE10 (Mg-1Zn-0.2Ce $)^{8,9}$. This is the well-known issue of the "strength-formability trade-off dilemma" in $\mathrm{Mg}$ and other sheet alloys. Thus, it is of great importance to challenge this dilemma and develop a low-cost Mg alloy with both high tensile properties and RT formability.

Magnesium sheet alloys generally have better formability in solution-treated conditions if their annealed texture is weakened; however, they would exhibit low yield strength due to the recovery and recrystallization of their plastically deformed microstructures ${ }^{10}$. Until recently, only a limited number of solution-treated $\mathrm{Mg}$ sheet alloys can be substantially strengthened via a bake-hardening treatment (2\% pre-strain and aging for $20 \mathrm{~min}$ at $170^{\circ} \mathrm{C}^{11}$ ). Such strengthening is attributed to the segregation of solutes to dislocations, as well as the formation of co-clusters of solutes ${ }^{11,12}$ during baking. However, no research has been reported for developing good RT-formable Mg sheet alloys which may be strengthened rapidly and substantially via a low-cost artificial aging treatment rather than via a bake-hardening treatment. The development of heat-treatable $\mathrm{Mg}$ sheet alloys with excellent RT-formability and subsequently rapid age-hardenability is therefore a promising approach to overcome the strength and formability trade-off dilemma ${ }^{13}$. The $\mathrm{Mg}-\mathrm{Al}-\mathrm{Zn}-\mathrm{Mn}$-Ca system ${ }^{11,12,14}$ is a promising alloy system to overcome this strength-formability trade-off. Also, trace additions of rare-earth elements like yttrium $(\mathrm{Y})$, neodymium $(\mathrm{Nd})$ and cerium $(\mathrm{Ce})$ can significantly modify the texture and refine grain size to enhance the ductility and formability of wrought $\mathrm{Mg}$ alloys. The improvement could be attributed to decreasing the intrinsic stacking fault energy $\left(\mathrm{I}_{1} \mathrm{SFE}\right)^{15}$ to generate $<\mathrm{c}+\mathrm{a}>$ dislocations, decreasing critical resolved shear stress (CRSS) of pyramidal $<\mathrm{c}+\mathrm{a}>$ slip $^{16}$, or providing the randomized texture ${ }^{17}$. Thus, the $\mathrm{Mg}-\mathrm{Zn}$-Al-Ca-Mn-Ce system is studied with a trace addition of Ce in this work, based on our earlier work ${ }^{18}$.

Extensive research has been reported on discovering mechanical behaviors and improving alloy performance via optimizing alloy composition and thermomechanical processing (TMP) ${ }^{18-23}$. CALPHAD (CALculation 


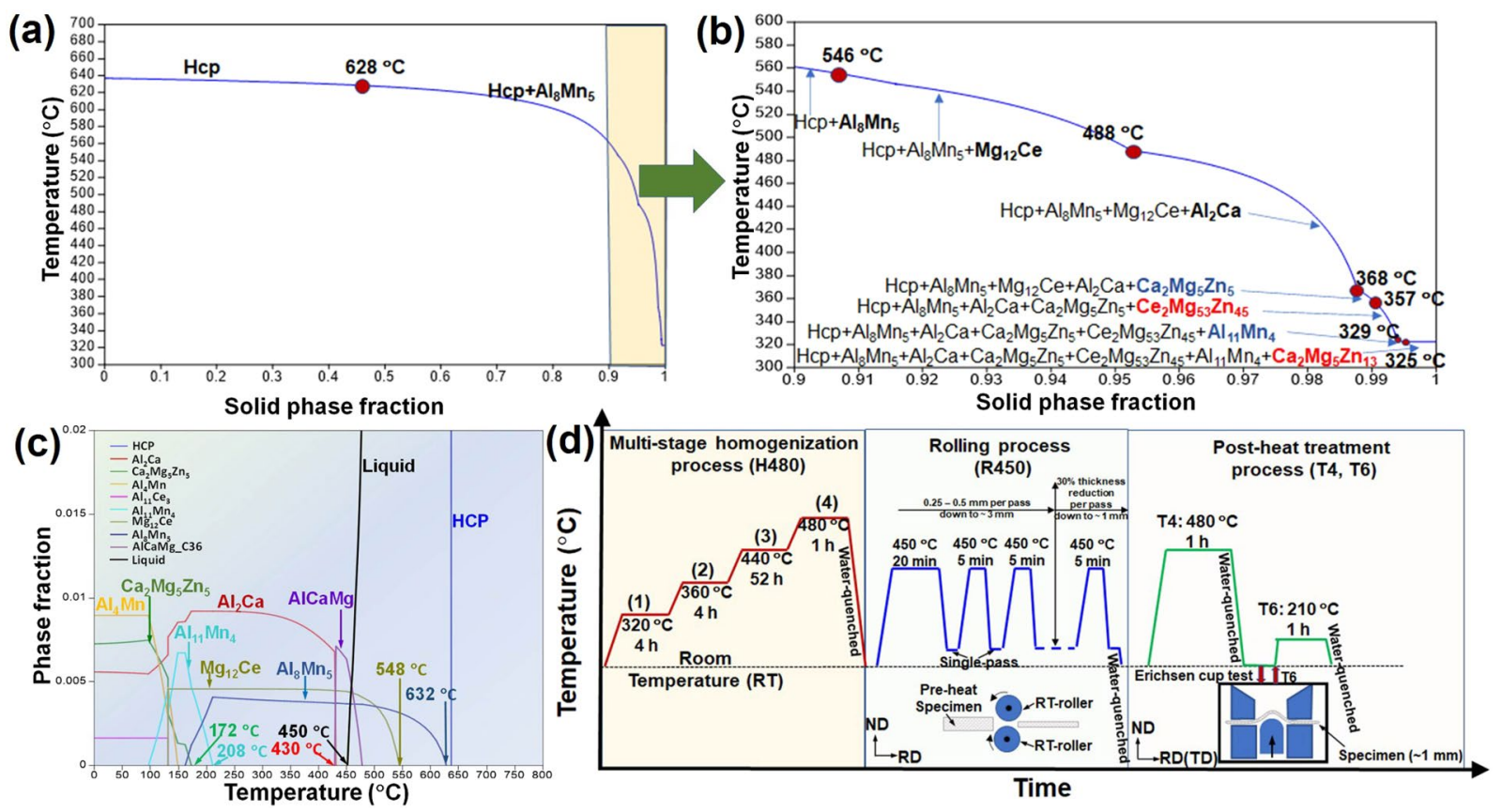

Figure 1. (a) Predicted solidification path; (b) The enlarged solidification path from the selection in (a); (c) equilibrium phase fraction vs. temperature calculations; and (d) thermomechanical processes for producing ZAXME11100 sheet alloy.

of Phase Diagrams) modeling ${ }^{24-27}$, as a part of Integrated Computational Materials Engineering (ICME) ${ }^{28}$ framework, has been successfully applied to study the alloying-processing-structure-property relationships in multicomponent alloy systems. Therefore, CALPHAD simulation is used to design a new Mg-1Zn-1Al-0.5Ca$0.4 \mathrm{Mn}-0.2 \mathrm{Ce}$ alloy (hereafter designed as ZAXME11100) and its optimal TMP to obtain more balanced strength, ductility and formability in this study. TMP (including homogenization, rolling and annealing) is critically important in optimizing the alloying effects for the final mechanical properties of the alloy. For example, conventional homogenization process (at below solidus temperature of the alloy to avoid incipient melting) is inefficient in dissolving second phases from the as-cast microstructure and maximizing the solute concentrations in the $\mathrm{Mg}$ matrix, thus achieving the overall alloying effects.

In this paper, CALPHAD simulation is used to design a new homogenization process (with multiple isothermal stages including final stages at temperatures higher than the alloy solidus ${ }^{18}$ ) for the new alloy, achieving maximum dissolution of alloying elements without incipient melting. The combination of the new alloy design and the multi-stage TMP process leads to the optimum combination of strength, ductility and formability of the new alloy.

\section{Results and discussions}

CALPHAD software Thermo-Calc and TCMG5 and MOBMG1 databases ${ }^{29}$ was used to perform the thermodynamic and kinetic modeling of ZAXME11100 alloy. Figure 1(a) shows the solidification path of ZAXME11100 alloy using the classical Scheil model, and an enlarged region near the end of solidification is shown in Fig. 1(b). The results show that HCP (hexagonal closed packed) $\mathrm{Mg}$ phase will form as a primary phase at $638^{\circ} \mathrm{C}$, followed by the formation of $\mathrm{Al}_{8} \mathrm{Mn}_{5}, \mathrm{Mg}_{12} \mathrm{Ce}, \mathrm{Al}_{2} \mathrm{Ca}, \mathrm{Ca}_{2} \mathrm{Mg}_{5} \mathrm{Zn}_{5}, \mathrm{Ce}_{2} \mathrm{Mg}_{53} \mathrm{Zn}_{45}, \mathrm{Al}_{11} \mathrm{Mn}_{4}$ and $\mathrm{Ca}_{2} \mathrm{Mg}_{5} \mathrm{Zn}_{13}$ phases at $628^{\circ} \mathrm{C}, 546^{\circ} \mathrm{C}, 488^{\circ} \mathrm{C}, 368^{\circ} \mathrm{C}, 357^{\circ} \mathrm{C}, 329^{\circ} \mathrm{C}$ and $325^{\circ} \mathrm{C}$, respectively. Figure $1(\mathrm{c})$ is the equilibrium phase fraction vs. temperature calculation for ZAXME11100 alloy, and the solidus temperature of ZAXME11100 alloy is shown as $450^{\circ} \mathrm{C}$. The calculated formation temperatures of $\mathrm{Al}_{8} \mathrm{Mn}_{5}$ and $\mathrm{Mg}_{12} \mathrm{Ce}$ are $632^{\circ} \mathrm{C}$ and $548^{\circ} \mathrm{C}$, respectively, in Fig. 1(c), which are slightly higher than those $\left(628^{\circ} \mathrm{C}\right.$ and $546^{\circ} \mathrm{C}$, respectively) of the same phases during cooling (solidification) in Fig. 1(a,b). Similarly, the formation of $\mathrm{Al}_{2} \mathrm{Ca}, \mathrm{Ca}_{2} \mathrm{Mg}_{5} \mathrm{Zn}_{5}$ and $\mathrm{Al}_{11} \mathrm{Mn}_{4}$ is at $430^{\circ} \mathrm{C}$, $172^{\circ} \mathrm{C}$, and $208^{\circ} \mathrm{C}$, respectively, which is considerably lower than their temperatures $\left(488^{\circ} \mathrm{C}, 368^{\circ} \mathrm{C}\right.$, and $\left.329^{\circ} \mathrm{C}\right)$ of formation during solidification in Fig. $1(\mathrm{a}, \mathrm{b})$. On the other hand, $\mathrm{Ce}_{2} \mathrm{Mg}_{53} \mathrm{Zn}_{45}$ and $\mathrm{Ca}_{2} \mathrm{Mg}_{5} \mathrm{Zn}_{13}$ phases formed during solidification in Fig. 1(b) are not shown in the equilibrium calculation in Fig. 1(c), thus they are assumed to be metastable phases.

Based on these results, a new homogenization profile (designated as $\mathrm{H} 480$, thereafter) was designed with four isothermal stages $\left(320^{\circ} \mathrm{C}\right.$ for $4 \mathrm{~h}, 360^{\circ} \mathrm{C}$ for $4 \mathrm{~h}, 440^{\circ} \mathrm{C}$ for $52 \mathrm{~h}$ and $480^{\circ} \mathrm{C}$ for $1 \mathrm{~h}$ ) to sequentially dissolve the intermetallic phases while avoiding incipient melting. The first stage was designed as $320^{\circ} \mathrm{C}$ between the formation temperatures of stable phases $\left(\mathrm{Ca}_{2} \mathrm{Mg}_{5} \mathrm{Zn}_{5}\right.$ at $172^{\circ} \mathrm{C}$; and $\mathrm{Al}_{11} \mathrm{Mn}_{4}$ at $\left.208^{\circ} \mathrm{C}\right)$ in Fig. $1(\mathrm{c})$ and the solidified phases $\left(\mathrm{Ca}_{2} \mathrm{Mg}_{5} \mathrm{Zn}_{5}\right.$ at $368^{\circ} \mathrm{C}$; and $\mathrm{Al}_{11} \mathrm{Mn}_{4}$ at $\left.329^{\circ} \mathrm{C}\right)$ in Fig. $1(\mathrm{~b})$, to initially dissolve the stable phases $\left(\mathrm{Ca}_{2} \mathrm{Mg}_{5} \mathrm{Zn}_{5}\right.$ and $\left.\mathrm{Al}_{11} \mathrm{Mn}_{4}\right)$ and the metastable phases $\left(\mathrm{Ce}_{2} \mathrm{Mg}_{53} \mathrm{Zn}_{45}\right.$ and $\left.\mathrm{Ca}_{2} \mathrm{Mg}_{5} \mathrm{Zn}_{13}\right)$. The second stage was 

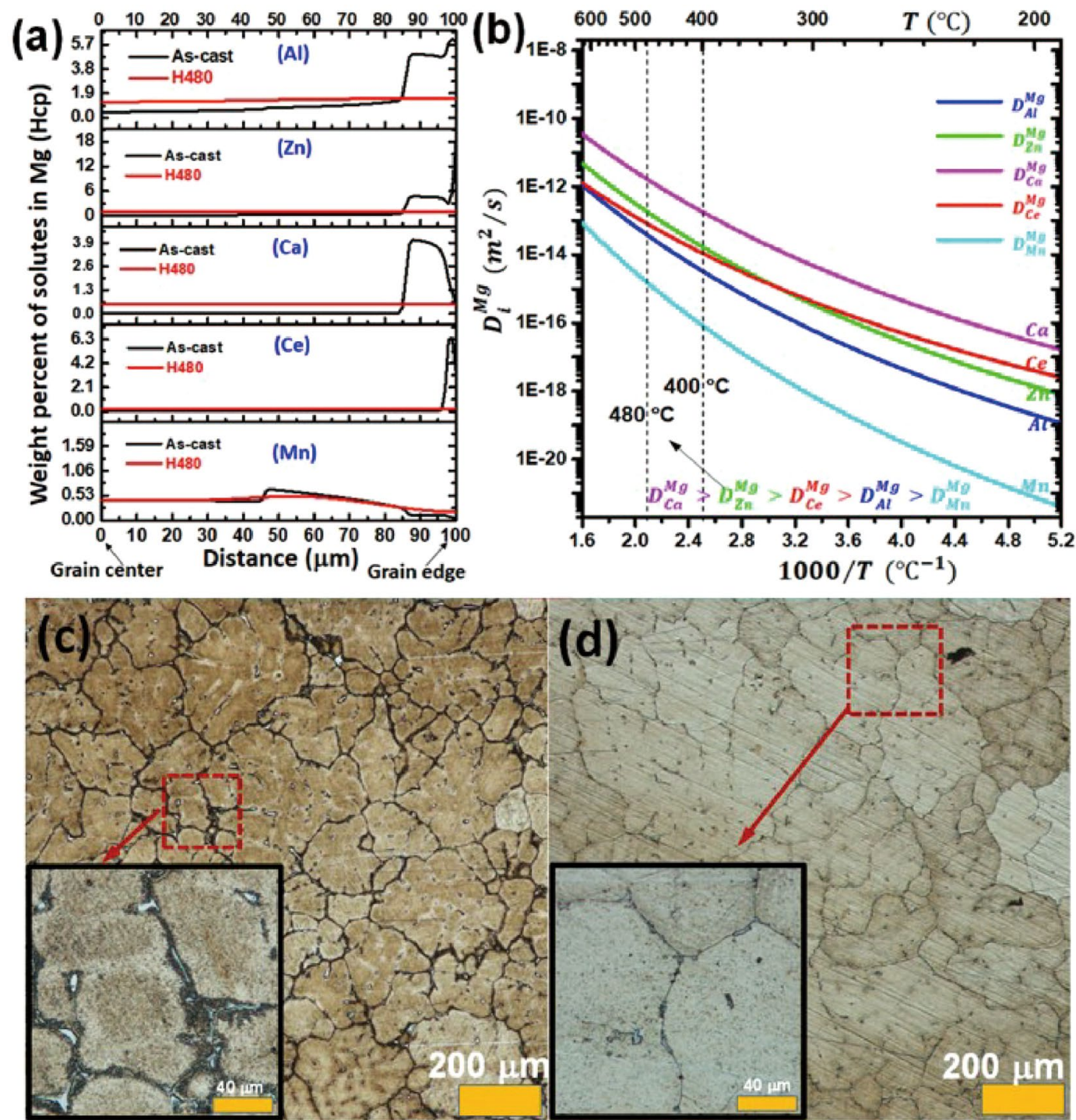

Figure 2. (a) Diffusion modeling of solutes $\mathrm{Al}, \mathrm{Zn}, \mathrm{Ca}, \mathrm{Ce}$ and $\mathrm{Mn}$ in $\mathrm{Mg}$ (hcp) using DICTRA software; (b) solute diffusion coefficients in $\mathrm{Mg}$ (hcp); optical micrographs of (c) as-cast condition; and (d) after H480 homogenization.

done at $360^{\circ} \mathrm{C}$ for $4 \mathrm{~h}$ to further dissolve the phases with higher melting temperatures, such as $\mathrm{Ca}_{2} \mathrm{Mg}_{5} \mathrm{Zn}_{5}$ phase $\left(368^{\circ} \mathrm{C}\right)$ in Fig. $1(\mathrm{~b})$ and also reduce the micro-segregation of alloying elements.

The third stage was carried out at $440^{\circ} \mathrm{C}$ for $52 \mathrm{~h}$ between the formation temperature of $\mathrm{Al}_{2} \mathrm{Ca}\left(430^{\circ} \mathrm{C}\right)$ in Fig. 1(c) and $\left(488^{\circ} \mathrm{C}\right)$ in Fig. 1(b), to dissolve $\mathrm{Al}_{2}$ Ca phase and further homogenize the alloying elements. Figure 1 (c) shows a small fraction of liquid at temperatures above the solidus $450^{\circ} \mathrm{C}$. Also, a new phase $\mathrm{AlCaMg}$ would possibly form during this stage since it is thermodynamically stable between $430^{\circ} \mathrm{C}$ and $478^{\circ} \mathrm{C}$ in Fig. 1 (c). Thus, the fourth stage was chosen as $480^{\circ} \mathrm{C}$ for $1 \mathrm{~h}$ to dissolve $\mathrm{AlCaMg}$ and potentially $\mathrm{Mg}_{12} \mathrm{Ce}$ and $\mathrm{Al}_{8} \mathrm{Mn}_{5}$ phases with higher thermal stability up to $548^{\circ} \mathrm{C}$ and $632^{\circ} \mathrm{C}$, respectively. However, the liquid phase was not experimentally observed during the fourth stage $\left(480^{\circ} \mathrm{C}, 1 \mathrm{~h}\right)$. The reason could be: (1) the homogenization time was not long enough for the liquid phase to form; or (2) the amount of the liquid phase formed was too small $(<\sim 1 \%$, $480^{\circ} \mathrm{C}$ in Fig. $1(\mathrm{c})$ ). Thus, the multi-stage homogenization profile (H480) and rolling process (R450) used in producing the ZAXME 11100 alloy sheet are summarized in Fig. 1(d).

Diffusion-controlled distribution of solutes $\mathrm{Al}, \mathrm{Zn}, \mathrm{Ca}, \mathrm{Ce}$ and $\mathrm{Mn}$ in $\mathrm{Mg}$ matrix was studied using DICTRA ${ }^{29}$ simulation, and Fig. 2(a) plots the calculated solute distributions in both the as-cast (AC) condition and the new H480-homogenized condition. The results demonstrate that the new multi-stage treatment is very effective in dissolving solute elements in $\mathrm{Mg}$ grain interiors. Figure 2(b) shows that the diffusion coefficients of $\mathrm{Al}, \mathrm{Zn}, \mathrm{Ca}$, $\mathrm{Mn}$ and Ce solutes in ZAXME11100 alloy are exponentially related to temperature. For example, the diffusion coefficients of the solutes at $480^{\circ} \mathrm{C}$ are about 10 times higher than those at $400^{\circ} \mathrm{C}$ close to the solidus temperature $\left(450^{\circ} \mathrm{C}\right.$ ), suggesting that significantly faster homogenization is possible at $480^{\circ} \mathrm{C}$ compared to $400^{\circ} \mathrm{C}$ (which is below the $450^{\circ} \mathrm{C}$ solidus temperature). It is also noted that $\mathrm{Al}$ and $\mathrm{Mn}$ have the lowest diffusion coefficients 

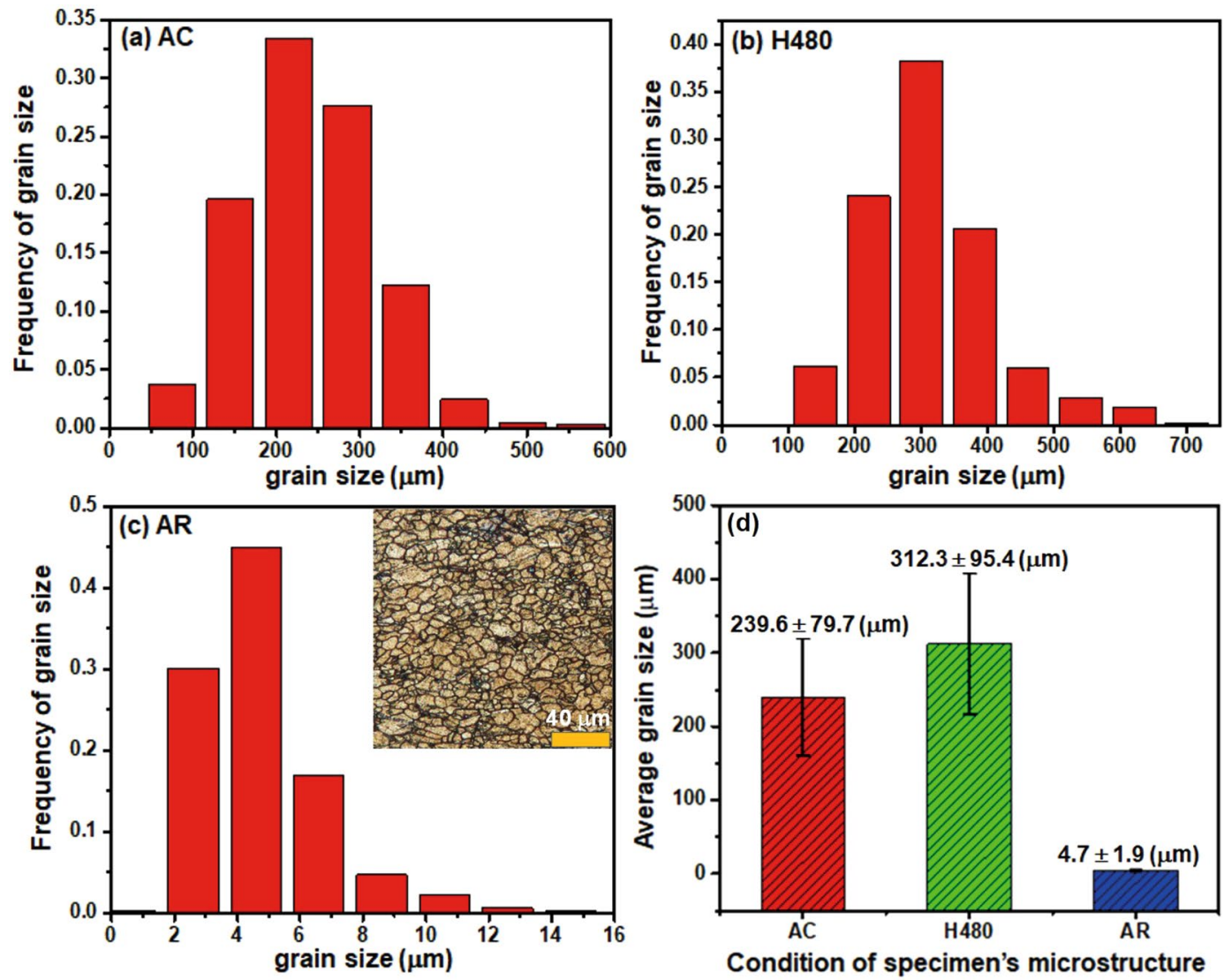

Figure 3. Grain size evolution during different thermomechanical processing: (a) AC (as-cast); (b) H480 homogenization; (c) AR (as-rolled); and (d) comparison of average grain sizes at AC, H480 and AR conditions.

among all alloying elements in $\mathrm{Mg}$, which also explains that $\mathrm{Al}_{8} \mathrm{Mn}_{5}$ is the most difficult phase to be dissolved during solution treatment.

Microstructures of ZAXME11100 alloy after as-cast condition and the new homogenization treatment (H480) were observed via optical microscopy and shown in Fig. 2(c,d), respectively. The results showed that the second phase particles near and along the grain boundaries have been essentially dissolved after the new homogenization profile (H480). However, a small amount of residual particles, mostly $\mathrm{Al}_{8} \mathrm{Mn}_{5}$ and a very few $\mathrm{Al}_{2} \mathrm{Ca}$ as identified in TEM, are still visible in Fig. 2(d).

The new Mg alloy solutionized at $\mathrm{H} 480$ heat treatment has been rolled following the designed rolling process (R450) in Fig. 1(d). The grain size of microstructure from as-cast (AC), H480 and as-rolled (AR) conditions is shown in Fig. 3. It should be noted that (1) the grain size at $\mathrm{H} 480$ solution treatment has slightly grown to $312.3 \mu \mathrm{m}$, which could be attributed to the inhibition of thermally stable $\mathrm{Al}_{8} \mathrm{Mn}_{5}$ and $\mathrm{Al}_{2} \mathrm{Ca}$ particles formed during the solidification; and (2) the grain size has been significantly decreased to $4.7 \mu \mathrm{m}$ at as-rolled condition due to recrystallization of the deformed microstructure.

The EBSD inverse pole figure (IPF) map overlaid by large angle grain boundaries with misorientation angles larger than 15 degrees in Fig. 4(a) shows the microstructure of ZAXME11100 alloy after rolling process (R450) followed by the post-forming solution treatment (T4) and water quenching from Fig. 1(d). The average grain size of ZAXME11100 alloy determined via EBSD is about $9.6 \mu \mathrm{m}$. It can be seen that the combination of rolling (R450) with the post-forming solution-treatment (T4) yields significant grain refinement in ZAXME11100 alloy. The texture pole figures of solution-treated (T4) microstructure are shown in Fig. 4(b). The microstructure has a weak split basal texture with a maximum intensity of $3.3 \mathrm{mrd}$. The maximum intensity of basal poles is also tilted by about \pm 40 degrees away from the normal direction (ND) and toward the transverse direction (TD). Such fine grain size and weakened texture of solution-treated (T4) ZAXME11100 sheet alloy contribute to both high ductility and formability ${ }^{11,14}$.

The high-angle annular dark-field (HAADF) STEM image in Fig. 5(a) shows a high density of intermetallic particles in the post-forming T4 microstructure. STEM energy dispersive spectroscopy (EDS) elemental maps were collected from the region showing in Fig. 5(a). The STEM-EDS elemental maps in Fig. 5(b-f) show that the nano-scale rod precipitates are enriched with $\mathrm{Al}$ and $\mathrm{Mn}$ elements. Elements $\mathrm{Zn}$, Ca and Ce (not shown in Fig. 5 due to small amount) are homogeneously distributed in the grain interior, suggesting that those alloying elements are dissolved in $\mathrm{Mg}$ matrix, hypothesized to form solute co-clusters ${ }^{11,12}$ during subsequent aging heat treatments and thereby contribute to strengthening of the ZAXME11100 alloy. 


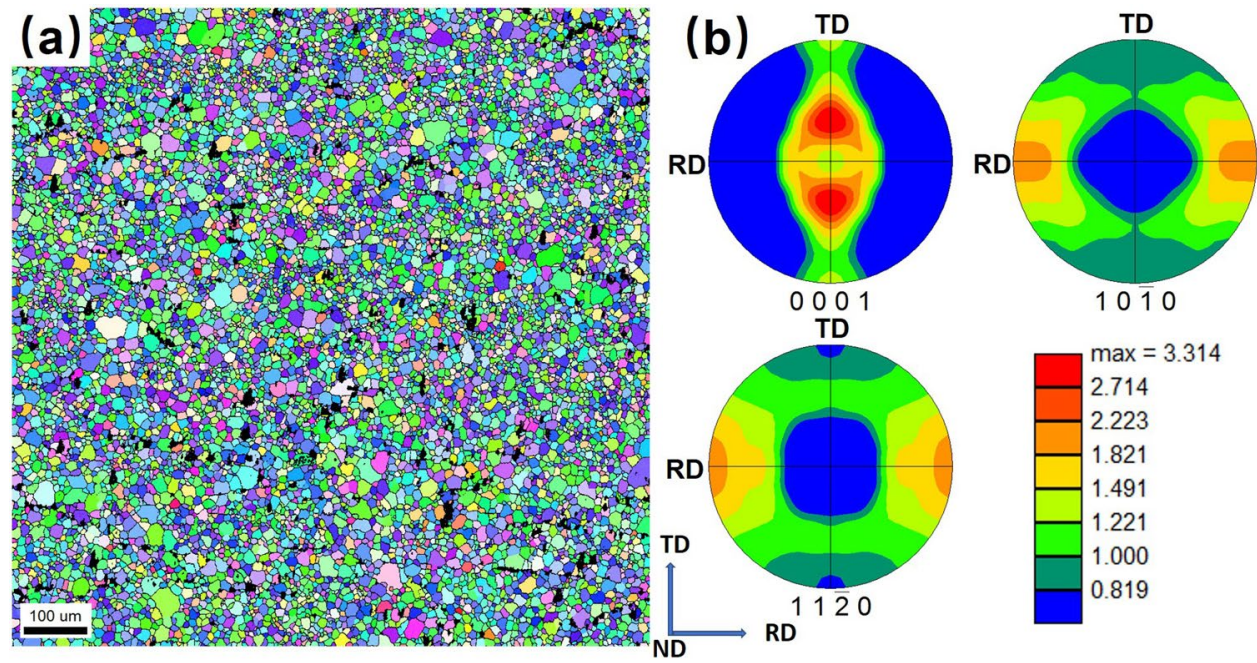

Figure 4. Characterization of the microstructure of ZAXME11100 alloy after solution-treated (T4) at $480^{\circ} \mathrm{C}$ for 1 hour: (a) EBSD IPF map; (b) texture pole figures; (For interpretation of the references to colors in this figure legend, the reader is referred to the web version of this article).
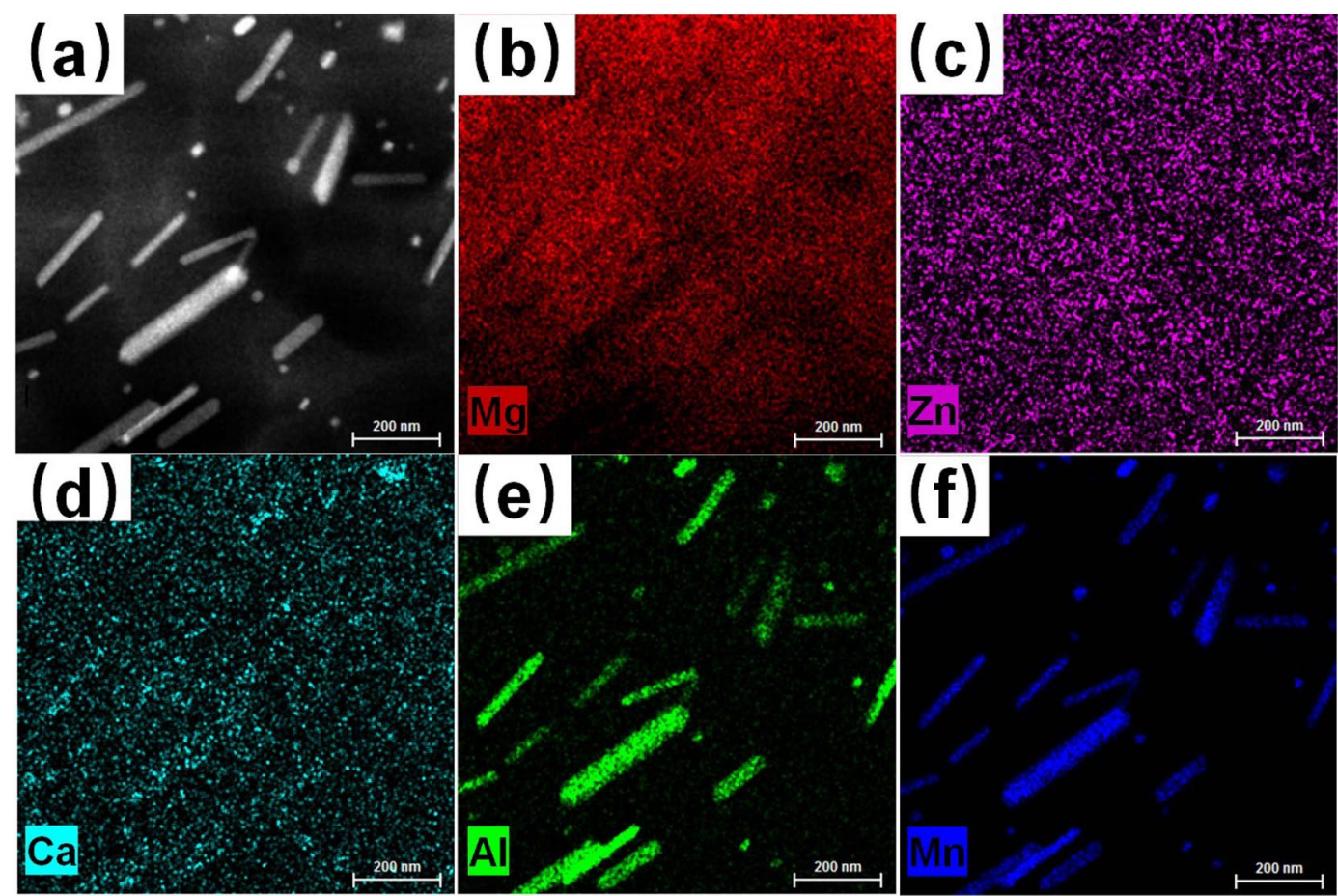

Figure 5. Characterization of the microstructure of ZAXME11100 alloy after solution-treated (T4) at $480^{\circ} \mathrm{C}$ for 1 hour: (a) HAADF-STEM image; (b-f) the corresponding STEM-EDS maps for solute elements (Mg-Red, Zn-Magenta, Ca-Turquoise, Al-Green, Mn-Blue).

Bright-field (BF) STEM image in Fig. 6(a) reveals that the T4 microstructure consists of a high density of uniformly distributed nano-size rod precipitates randomly distributed both within grain interior and at grain boundaries. Bright field (BF) TEM image with an inset selected diffraction patter in Fig. 6(b) shows that the rod precipitates are $\mathrm{Al}_{8} \mathrm{Mn}_{5}$ phase. As shown in Fig. $1(\mathrm{~b}, \mathrm{c}), \mathrm{Al}_{8} \mathrm{Mn}_{5}$ starts to form at $628^{\circ} \mathrm{C}$ during solidification and melt at $632^{\circ} \mathrm{C}$ under the post-heat treatment. It cannot be dissolved during solution treatment at $480{ }^{\circ} \mathrm{C}$. Therefore, $\mathrm{Al}_{8} \mathrm{Mn}_{5}$ can retard grain growth through Zener pinning during annealing at $480^{\circ} \mathrm{C}$, thus contributing to grain refinement. High density and uniformly distributed $\mathrm{Al}_{8} \mathrm{Mn}_{5}$ phase also contribute to the strength of T4 microstructure.

Figure 7(a) shows the variation in the Vickers hardness of solution-treated (T4) ZAXME11100 sheet alloy under the artificial aging at $210^{\circ} \mathrm{C}$. The ZAXME11100 sheet alloy has a hardness value of $56.0 \pm 2.1 \mathrm{HV}$ in the 

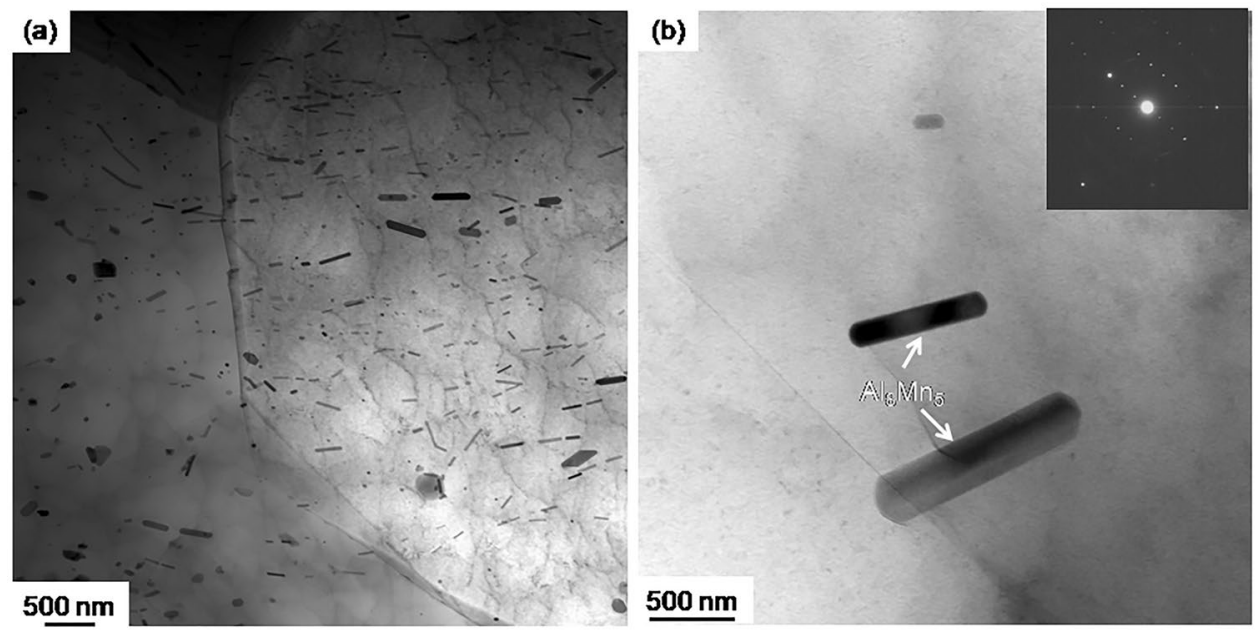

Figure 6. Characterization of the microstructure of ZAXME11100 alloy after solution-treated (T4) at $480^{\circ} \mathrm{C}$ for 1 hour: (a) BF-STEM image; (b) BF-TEM image with an inset selected area diffraction pattern along [113] zone axis of $\mathrm{Al}_{8} \mathrm{Mn}_{5}$ precipitates.
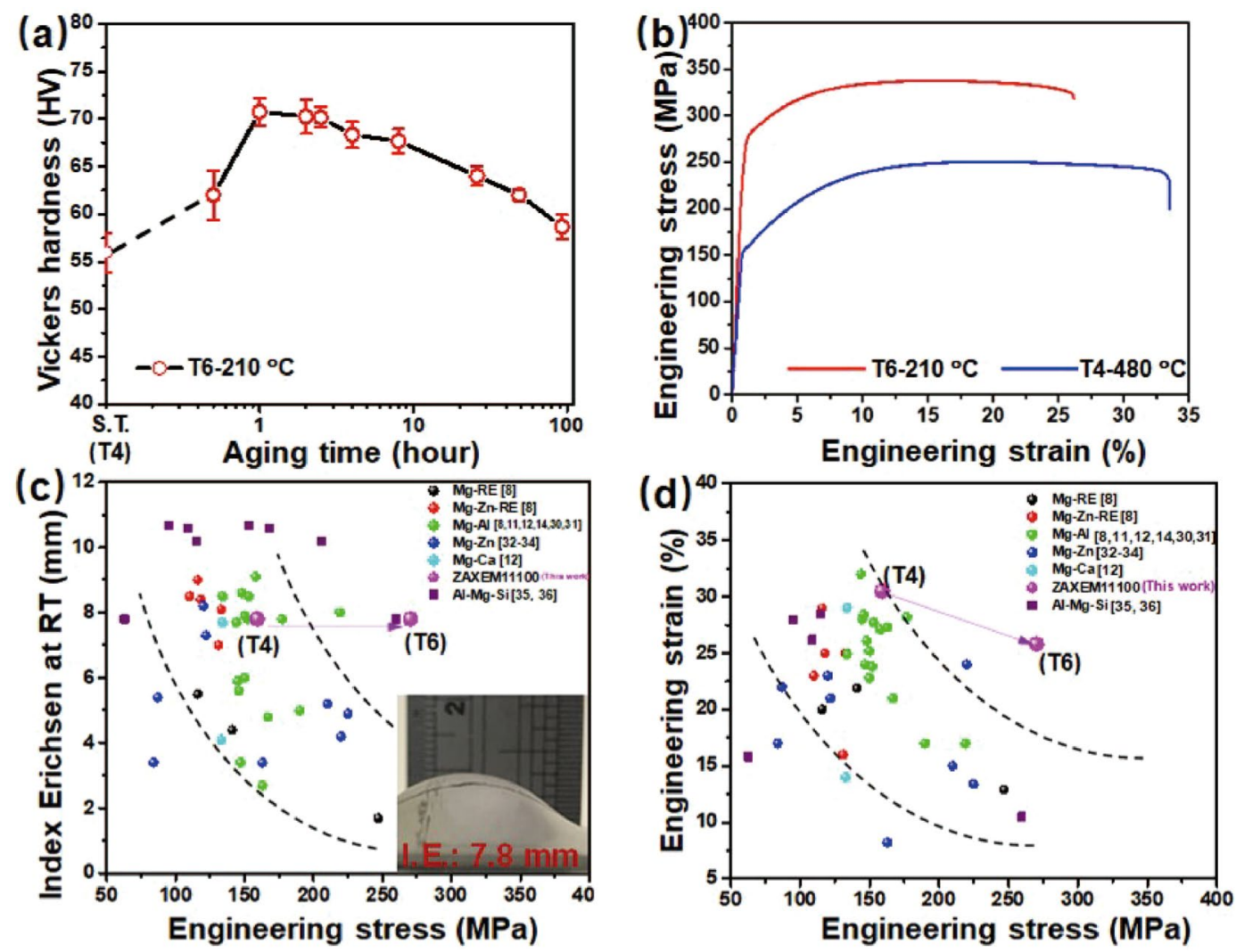

Figure 7. (a) Age hardening response at $210^{\circ} \mathrm{C}$; (b) tensile curve from the $\mathrm{T} 4$ and peak-aged $\mathrm{T} 6$ treated ZAXME11100 alloy samples; (c) plot of I.E. at RT value as a function of engineering stress; (d) plot of engineering strain vs engineering stress at RT.

solution treated condition (T4) from Fig. 1(d) and exhibits a rapid age-hardening to a peak hardness of $70.8 \pm 1.5$ $\mathrm{HV}$ for $1 \mathrm{~h}$. The tensile curves obtained from solution-treated (T4) and peak-aged (T6) samples are shown in Fig. 7(b). The mechanical properties of these samples are summarized in Table 1. The T4 treated ZAXME11100 sheet alloy exhibits a moderate yield strength (Y.S.) of $159 \mathrm{MPa}$ and an ultimate tensile strength (U.T.S.) of $253 \mathrm{MPa}$ with an extraordinarily high elongation of $31 \%$ and Index Erichsen (I.E.) value of $7.8 \mathrm{~mm}$. After the T6 heat-treatment, the yield strength (Y.S.) and ultimate tensile strength (U.T.S.) have been significantly improved to $270 \mathrm{MPa}$ and $332 \mathrm{MPa}$ with a high elongation of $26 \%$. Figure $7(\mathrm{c}, \mathrm{d})$, respectively, summary the engineering 


\begin{tabular}{|l|l|l|l|l|}
\hline Heat treatment & Y.S. (MPa) & $\begin{array}{l}\text { U.T.S. } \\
(\mathbf{M P a})\end{array}$ & $\begin{array}{l}\text { Elongation } \\
(\mathbf{\%})\end{array}$ & $\begin{array}{l}\text { I.E. } \\
(\mathbf{m m})\end{array}$ \\
\hline $\mathrm{T} 4-480^{\circ} \mathrm{C}, 1 \mathrm{~h}$ & $159.2 \pm 2.5$ & $252.6 \pm 2.3$ & $30.5 \pm 3.1$ & $7.8 \pm 0.1$ \\
\hline $\mathrm{T} 6-210^{\circ} \mathrm{C}, 1 \mathrm{~h}$ & $270.3 \pm 0.4$ & $332.4 \pm 5.3$ & $25.8 \pm 1.8$ & \\
\hline
\end{tabular}

Table 1. Mechanical properties of ZAXME11100 sheet alloy at room temperature.

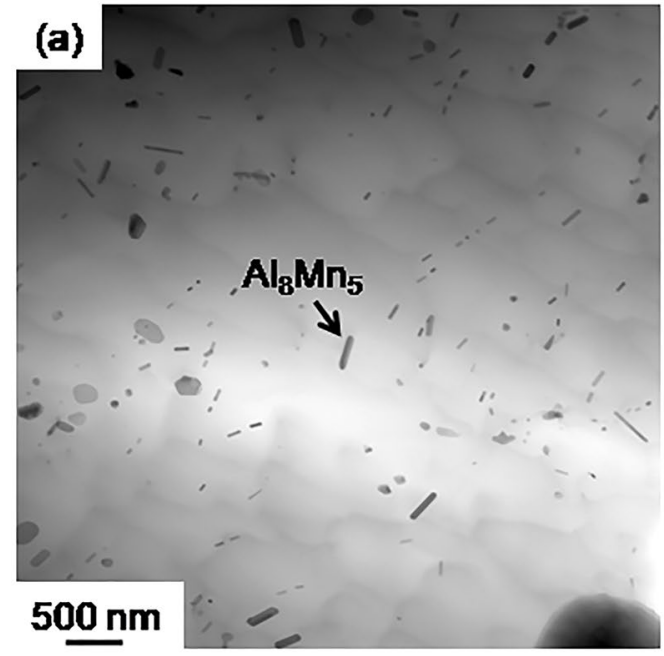

(c)

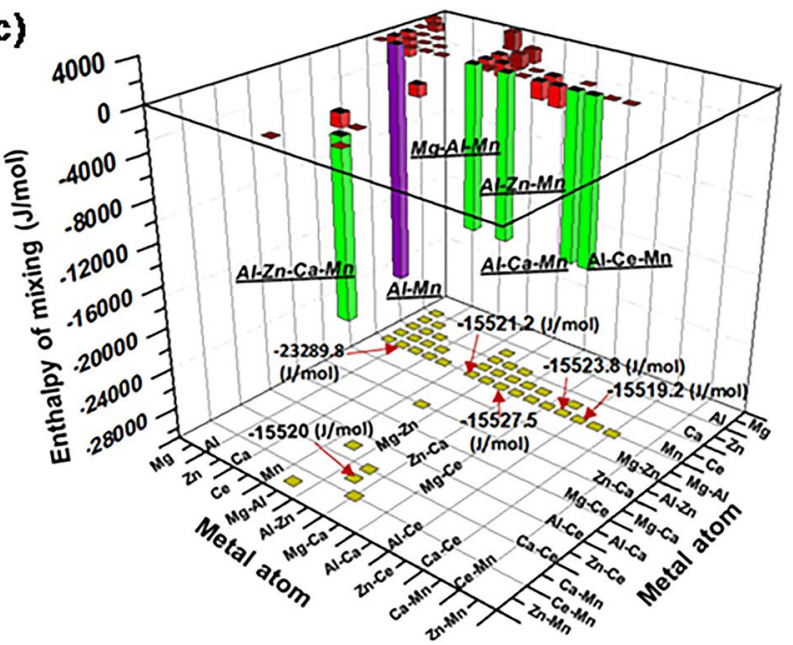

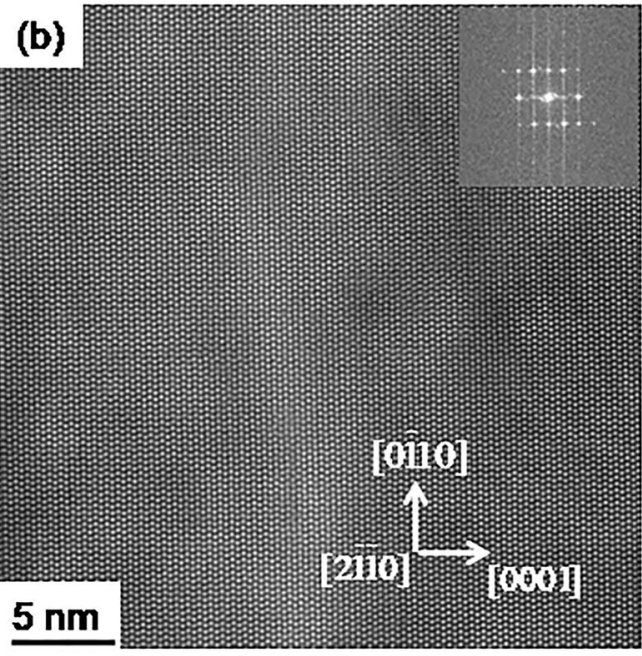

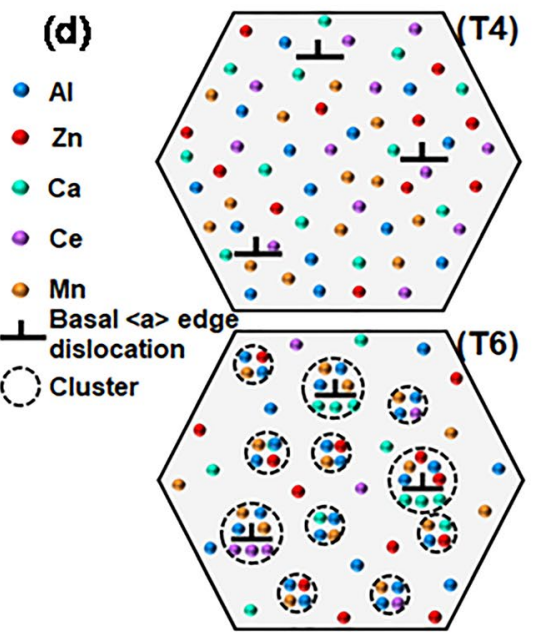

Figure 8. Characterization of microstructure of ZAXME11100 alloy after aging treatment (T6) at $210^{\circ} \mathrm{C}$ for 1 hour: (a) bright field STEM image; (b) atomic resolution HAADF-STEM image; (c) projection of mixing enthalpy of various equiatomic pairs in $\mathrm{Mg}(\mathrm{hcp}$ ) matrix; (d) top-T4: solute atoms dissolve into $\mathrm{Mg}(\mathrm{hcp})$ after solution treatment and bottom-T6: solute atoms not only segregate to basal $<\mathrm{a}>$ dislocations but also form small clusters during a short aging time.

stress as a function of I.E. values as well as engineering strain for various $\mathrm{Mg}^{8,11,12,14,30-34}$ and $\mathrm{Al}^{35,36}$ sheet alloys. As can been seen, the ZAXME11100 sheet alloy shows good stretch formability in T4 condition, which is close to that reported for 6000 series $\mathrm{Al}$ alloy ${ }^{35,36}$. Subsequently the artificial aging (T6) treatment substantially increases the engineering stress with less reduction of ductility, enabling this alloy to have a well-balanced high strength, ductility and formability at room temperature.

The preliminary STEM imaging in Fig. 8(a,b) for the T6 microstructure of ZAXME11100 alloy did not reveal the formation of crystalline precipitate phases, except for the nano-size $\mathrm{Al}_{8} \mathrm{Mn}_{5}$ rods which were seen previously in the solution-treated samples (Fig. 6). This suggests that solutes $\mathrm{Al}$ and $\mathrm{Mn}$ have the strongest affinity in the ZAXME11100 alloy and that other solutes may not have enough strong affinity to form crystalline phases during aging. Figure 8(c) shows the enthalpy of mixing values of various atomic pairs in the ZAXME11100 system. The calculated result shows that the enthalpies of mixing of Al-Mn $(-23289.8 \mathrm{~J} / \mathrm{mol}), \mathrm{Al}-\mathrm{Zn}-\mathrm{Ca}-\mathrm{Mn}(-15520 \mathrm{~J} /$ $\mathrm{mol})$, Al-Ca-Mn (-15523.8 J/mol), Al-Ce-Mn (-15519.2 J/mol), Al-Zn-Mn (-15527.5 J/mol), and Mg-Al-Mn 
$(-15521.2 \mathrm{~J} / \mathrm{mol})$ pairs are significantly negative. Therefore, thermodynamically, there is a strong affinity between the corresponding solutes to form solute clusters or crystalline phases. It should be noted that the Al-Mn pair has the most negative enthalpy of mixing, suggesting that solute pair $\mathrm{Al}$ and $\mathrm{Mn}$ has a much stronger affinity than other solute pairs, and therefore is most likely to form crystalline precipitates.

Based on results from Fig. 8(a-c), the Al-Mn atomic pair with strongest affinity would form crystalline $\mathrm{Al}_{8} \mathrm{Mn}_{5}$ phase. Other atomic pairs with negative mixing enthalpies may form some clusters ${ }^{11,12}$ without forming distinct observable precipitates during the ageing treatment. Further characterization work is on-going to investigate the strengthening mechanism involved in T6 treatment. Therefore, the significant enhancement of engineering strength after T6 treatment would be attributed to the formation of solute clusters ${ }^{11,12}$ in Fig. 8(d), which should provide a string pinning effect on the basal $<\mathrm{a}>$ dislocations. These dislocations need a larger force to break away from the solute atmosphere after aging (T6). Therefore, the combination of designing new alloy and optimizing TMP with CALPHAD methodology has led to a heat-treatable magnesium sheet alloy (ZAXME11100) with excellent RT-formability and high strength, which has overcome the well-known strength-formability dilemma.

\section{Conclusions}

In summary, a new Mg sheet alloy (ZAXME11100: Mg-1Zn-1Al-0.5Ca-0.4Mn-0.2Ce) and a novel thermomechanical process have been developed based on CALPHAD and diffusion modeling in combination with experimental investigation. The new Mg sheet alloy produced via low-cost rolling followed by a multi-stage solution treatment (T4) and conventional aging treatment (T6) has a superior combination of high strength (270 MPa in T6), ductility (31\% in T4) and formability (Erichsen Index of $7.8 \mathrm{~mm}$ in T4) at room temperature. Microstructure characterization and thermodynamic/kinetic calculations suggest that the following factors contribute to the excellent properties: (1) weak and split basal texture; (2) fine grain structure (average 9.6 $\mu \mathrm{m}$ ); and (3) possible formation of solute clusters after a short-time aging treatment (T6) due to the negative mixing enthalpy of various solute pairs. The new ZAXME11100 sheet alloy has successfully overcome the common trade-off relationship between formability/ductility and strength, promising high-volume automotive applications of magnesium sheet components.

\section{Materials and methods}

Magnesium sheet alloy preparation method was reported in a previous publication ${ }^{18}$. Mg- $1 \mathrm{Zn}-1 \mathrm{Al}-0.5 \mathrm{Ca}-0.4 \mathrm{Mn}$ $0.2 \mathrm{Ce}$ (ZAXME11100) alloy was prepared in a steel crucible under a protective gas mixture of $\mathrm{CO}_{2}$ and $\mathrm{SF}_{6}$, then cast at $750^{\circ} \mathrm{C}$ into a steel mold pre-heated to $400^{\circ} \mathrm{C}$ to produce $110 \times 114 \times 18 \mathrm{~mm}$ plates. The cast plates were machined into $20 \times 28 \times 7 \mathrm{~mm}$ samples which were homogenized (multi-stage H480) and water-quenched. The homogenized samples were cold-rolled initially to $\sim 3 \mathrm{~mm}$ with about 0.25 to $0.5 \mathrm{~mm}$ thickness reduction per pass, and then rolled to $\sim 1 \mathrm{~mm}$ with $30 \%$ thickness reduction per pass. Except for the final rolling pass, the samples were pre-heated at $450^{\circ} \mathrm{C}$ for $5 \mathrm{~min}$ prior to each pass. Longitudinal tensile samples with a gauge length of $12.5 \mathrm{~mm}$, a width of $5 \mathrm{~mm}$, and a thickness of $1 \mathrm{~mm}$ were machined from the as-rolled sheets. Some as-rolled tensile samples were solution-treated at $480^{\circ} \mathrm{C}$ for $1 \mathrm{~h}(\mathrm{~T} 4)$ followed by water-quenching and then artificial aging at $210^{\circ} \mathrm{C}$ for 100 hours in an oil bath. Age hardening responses of the solution-treated samples were measured using a Vickers hardness tester. Tensile tests were conducted at RT on the solution-treated (T4) and peak-aged (T6) samples at a strain rate of $1.8 \times 10^{-4} \mathrm{~s}^{-1}$. At least three specimens were tested at RT for each temper condition to ensure repeatability. To evaluate the stretch formability of the solution-treated (T4) sheets, Erichsen cupping tests were performed at RT on $60 \times 60 \mathrm{~mm}$ rectangular samples with a thickness of $1 \mathrm{~mm}$ using an Erichsen sheet metal testing machine with a $20 \mathrm{~mm}$ diameter hemispherical punch. The punch speed and blank-clamping force were around $6 \mathrm{~mm} / \mathrm{min}$ and $10 \mathrm{kN}$, respectively. Graphite lubrication was used on the tool.

The microstructure of the new alloy was characterized using optical microscopy, scanning electron microscopy (SEM), transmission electron microscopy (TEM) and scanning transmission electron microscopy (STEM). The SEM study and electron backscatter diffraction (EBSD) mapping were conducted using a FEI Apreo SEM equipped with a EDAX OIM system. Specimens for TEM analysis were mechanically ground to $\sim 40 \mu \mathrm{m}$ using a Fischione model 100 dimpler. Perforation of thin TEM foils were conducted in a Fischione model 1010 ion mill operating at a voltage of $5 \mathrm{keV}$. TEM and STEM investigations were carried out on a FEI Tecnai F20 TEM/STEM microscope operating at $200 \mathrm{kV}$. STEM-EDS elemental maps were collected using a FEI G2 60-300 TEM/STEM microscope equipped with a Super-X/ChemiSTEM) EDS system operating at $300 \mathrm{kV}$.

Received: 25 April 2020; Accepted: 27 May 2020;

Published online: 22 June 2020

\section{References}

1. Baker, L. J., Daniel, S. R. \& Parker, J. D. Metallurgy and processing of ultralow carbon bake hardening steels. Mater. Sci. Technol. 18, 355-368 (2002).

2. Birol, Y. Pre-aging to improve bake hardening in a twin-roll cast Al-Mg-Si alloy. Mater. Sci. Eng. A. 391, 175-180 (2005).

3. Pollock, T. M. Weight loss with magnesium alloys. Science. 328, 986-987 (2010).

4. Lu, K. The future of metals. Science. 328, 319-320 (2010).

5. Chino, Y., Sassa, K. \& Mabuchi, M. Tensile properties and stretch formability of Mg-1.5 mass\%- 0.2 mass $\%$ Ce sheet rolled at 723 K. Mater. Trans. 49, 1710-1712 (2008).

6. Chino, Y., Huang, X., Suzuki, K. \& Mabuchi, M. Enhancement of stretch formability at room temperature by addition of Ca in MgZn alloy. Mater. Trans. 51, 818-821 (2010).

7. Jiang, S. et al. Ultrastrong steel via minimal lattice misfit and high-density nanoprecipitation. Nature. 544, 460-464 (2017).

8. Suh, B. C., Shim, M. S., Shin, K. S. \& Kim, N. J. Current issues in magnesium sheet alloys: where do we go from here? Scr. Mater. 8485, 1-6 (2014).

9. Joost, W. J. \& Krajewski, P. E. Towards magnesium alloys for high-volume automotive applications. Scr. Mater. 128, 107-112 (2017).

10. Chino, Y. et al. Influence of Zn concentration on stretch formability at room temperature of Mg-Zn-Ce alloy. Mater. Sci. Eng. A. 528, 566-572 (2010). 
11. Bian, M. Z. et al. Bake-hardenable Mg-Al-Zn-Mn-Ca sheet alloy processed by twin-roll casting. Acta Mater. 158, 278-288 (2018).

12. Bian, M. Z. et al. A heat-treatable Mg-Al-Ca-Mn-Zn sheet alloy with good room temperature formability. Scr. Mater. 138, 151-155 (2017).

13. Hono, K., Mendis, C. L., Sasaki, T. T. \& Oh-ishi, K. Towards the development of heat treatable high-strength wrought Mg alloys. Scr. Mater. 63, 710-715 (2010).

14. Trang, T. T. T. et al. Designing a magnesium alloy with high strength and high formability. Nat. Commun. 9, 2522 (2018).

15. Sandlo"bes, S. et al. The relation between ductility and stacking fault energies in Mg and Mg-Y alloys. Acta Mater. 60, 3011-3021 (2012).

16. Liu, G. et al. Designing Mg alloys with high ductility: Reducing the strength discrepancies between soft deformation modes and hard deformation modes. Acta Mater. 141, 1-9 (2017).

17. Luo, A. A., Mishra, R. K. \& Sachdev, A. K. High-ductility magnesium-zinc-cerium extrusion alloys. Scr. Mater. 64, 410-413 (2011).

18. Shi, R., Miao, J. \& Luo, A. A. A new magnesium sheet alloy and its multi-stage homogenization for simultaneously improved ductility and strength at room temperature. Scr. Mater. 171, 92-97 (2019).

19. Shi, R., Zhu, Z. \& Luo, A. A. Assessing phase equilibria and atomic mobility of intermetallic compounds in aluminum-magnesium alloy system. J. Alloys. Compd. 825, 153962 (2020).

20. Su, C. et al. Enhanced ductility in high-pressure die casting Mg-4Ce-xAl-0.5Mn alloys via modifying second phase. Mater. Sci. Eng. A. 773, 138870 (2020).

21. Shi, R., Meier, J. \& Luo, A. A. Controlling particle/metal interactions in metal matrix composites during solidification: the role of melt viscosity and cooling rate. Metall. Mater. Trans. A. 50, 3736 (2019).

22. Mishra, A. et al. Theoretical Investigations on Structural Stability and Elastic Properties of MoNbTaW-X (=Ti/V) High Entropy Alloys. J. Mater. Sci. Res. and Rev. 4(2), 1-9 (2019).

23. Shi, R., Avey, T. \& Luo, A. A. A CALPHAD (CALculation of PHAse Diagrams)-based viscosity model for Al-Ni-Fe-Co melt system. J. Mol. Liq. 291, 111271 (2019).

24. Shi, R., Chandra, D., Chien, W. \& Wang, J. High-throughput thermodynamic computation and experimental study of solid-state phase transitions in organic multicomponent orientationally disordered phase change materials for thermal energy storage. CALPHAD. 64, 66-77 (2019).

25. Luo, A. A. Material design and development: From classical thermodynamics to CALPHAD and ICME approaches. CALPHAD. 50, 6-22 (2015).

26. Shi, R. \& Luo, A. Applications of CALPHAD modeling and databases in advanced lightweight metallic materials. CALPHAD. 62, 1-17 (2018).

27. Shi, R. Applications of CALPHAD (CALculation of PHAse Diagram) modeling in organic orientationally disordered phase change materials for thermal energy storage. Thermochim. acta. 683, 178461 (2020).

28. Pollock, TM. et al. Integrated Computational Materials Engineering: A Transformational Discipline for Improved Competitiveness and National Security, The National Academies Press, 500 Fifth Street, N.W. Washington, DC 20001, 2008.

29. https://www.thermocalc.com/ 2018.

30. Huang, X. S., Suzuki, K., Chino, Y. \& Mabuchi, M. Texture and stretch formability of AZ61 and AM60 magnesium alloy sheets processed by high-temperature rolling. J. Alloys. Compd. 632, 94-102 (2015).

31. Huang, X. S., Suzuki, K., Chino, Y. \& Mabuchi, M. Influence of aluminum content on the texture and sheet formability of AM series magnesium alloys. Mater. Sci. Eng. A. 633, 144-153 (2015).

32. Bhattacharjeea, T. et al. High strength and formable Mg-6.2 Zn-0.5 Zr- 0.2Ca alloy sheet processed by twin roll casting. Mater. Sci. Eng. A. 609, 154-160 (2014).

33. Yuasa, M. et al. Effects of group II elements on the cold stretch formability of Mg-Zn alloys. Acta Mater. 83, 294-303 (2015).

34. Chino, Y., Huang, X. S. \& Suzuki, K. J. Development of Room Temperature Formability of Rolled Magnesium Alloy Sheets by Texture Control. Jpn. Met. 81(2), 49-54 (2017).

35. Hirth, S. M., Marshall, G. J., Court, S. A. \& Lloyd, D. J. Effects of Si on the aging behaviour and formability of aluminium alloys based on AA6016. Mater. Sci. Eng. A. 319-321, 452-456 (2001).

36. Ozturk, F., Esener, E., Toros, S. \& Picu, C. R. Effects of aging parameters on formability of 6061-O alloy. Mater. Des. 31, 4847-4852 (2010).

\section{Acknowledgements}

The authors acknowledge Dr. Tracy D. Berman and Prof. John E. Allison of University of Michigan for conducting Erichsen cupping test, Randy Gerken of FiatChrysler, Bita Ghaffari of Ford Motor Company, Anil Sachdev and Jon Carter of General Motors and entire USAMP project team for many helpful discussions. This work is partially supported by the United States Automotive Materials Partnership (USAMP) and by the U.S. Department of Energy (DOE) National Energy Technology Laboratory under Award Number DE-EE0007756. This report was prepared as an account of work sponsored by an agency of the United States Government. Neither the United States Government nor any agency thereof, nor any of their employees, makes any warranty, express or implied, or assumes any legal liability or responsibility for the accuracy, completeness, or usefulness of any information, apparatus, product, or process disclosed, or represents that its use would not infringe privately owned rights. Reference herein to any specific commercial product, process, or service by trade name, trademark, manufacturer, or otherwise does not necessarily constitute or imply its endorsement, recommendation, or favoring by the United States Government or any agency thereof. The views and opinions of authors expressed herein do not necessarily state or reflect those of the United States Government or any agency thereof.

\section{Author contributions}

A.A. Luo supervised the research in this paper. A.A. Luo and R. Shi conceived alloy design and TMP processing. R. Shi and T. Avey prepared materials by casting and TMP, examined the optical microstructure and mechanical properties. R. Shi performed CALPHAD/kinetic simulation. J. Miao characterized the microstructure via SEM, EBSD and TEM techniques. All authors analyzed, discussed the results, and then wrote the paper.

\section{Competing interests}

The authors declare no competing interests.

\section{Additional information}

Correspondence and requests for materials should be addressed to A.A.L.

Reprints and permissions information is available at www.nature.com/reprints. 
Publisher's note Springer Nature remains neutral with regard to jurisdictional claims in published maps and institutional affiliations.

(c) (i) Open Access This article is licensed under a Creative Commons Attribution 4.0 International License, which permits use, sharing, adaptation, distribution and reproduction in any medium or format, as long as you give appropriate credit to the original author(s) and the source, provide a link to the Creative Commons license, and indicate if changes were made. The images or other third party material in this article are included in the article's Creative Commons license, unless indicated otherwise in a credit line to the material. If material is not included in the article's Creative Commons license and your intended use is not permitted by statutory regulation or exceeds the permitted use, you will need to obtain permission directly from the copyright holder. To view a copy of this license, visit http://creativecommons.org/licenses/by/4.0/.

(c) The Author(s) 2020 